\title{
Presence of Coliforms and Fecal Coliforms in Fast Food Items of Local Restaurants and Fast Food Outlets of Dhaka City
}

\author{
Mohammad Omar Faruk and Marufa Zerin Akhter* \\ Department of Microbiology, University of Dhaka
}

(Received 29 March 2011; Accepted 14 July 2011)

\begin{abstract}
The Microbiological status of $\mathbf{5 0}$ fast food samples collected from middle class and lower middle class retail outlets of fast food shops and restaurants at New Market and Dhanmondi area of Dhaka city were assessed. Eighty four percent of the samples were found to be satisfactory and $16 \%$ of the samples were found to be unsafe for human consumption. Total coliform, fecal coliform, Salmonella spp, Staphylococcus aureus and fungal count in $12 \%, 8 \%, 16 \%, 14 \%$ and $14 \%$ samples respectively have crossed the recommended limits and were unsafe for human consumption. Bare-handed handling of foods and use of unsafe water for dish washing and hand washing by food handlers, keeping food for long time under lighting in display glass boxes with elevated temperatures and storage of uncooked and half cooked meat items side by side in the refrigerator were noticed to be the possible sources and causes of microbiological contamination of the fast food items.
\end{abstract}

Keywords: Fast food, Fecal coliform, Total coliform

Fast food can be prepared and served very quickly. Typically the term refers to food sold in a restaurant or store and served to the customer in a packaged form for take-out or take-away. The main three reasons for taking fast foods are: a. time constraints $b$. being away from home $\mathrm{c}$. shortage of money.

Food with proper nutritional value, hygienic in quality and appropriate in quantity is essential for good health and active life ${ }^{1}$. People need a balanced diet containing different groups of foods such as carbohydrates, fats, proteins, vitamins, water and minerals in appropriate proportion so that an individual is assured of obtaining the minimum requirements of all the required nutrients ${ }^{2}$. While convenient and economical for a busy lifestyle, fast foods are typically high in saturated fat, sugar, and salt ${ }^{3}$. The disease agents spread by food not only incapacitate large groups of people but also sometimes result in serious disability and death. Roughly, 76 million people in the United States suffer from food borne illnesses yearly, 300,000 are hospitalized and 5,000 die, according to estimates from the Center for Disease Control and Prevention (USA). Children younger than 4 are sickened by food more than those in any other age group, but adults over age 50 suffer more hospitalizations and death as a result of foodrelated infections ${ }^{4}$.

Fast foods are gradually getting popularity in our country and hence, a huge number of fast food shops are operating; most of which are not aware of the hygienic practice associated with microbiological safety of food.

The basic idea behind the adoption of microbiological standards for foods is protection of the consumer from unnecessary food poisoning hazards as well as from deteriorating products ${ }^{5,6}$. This study aimed to determine the microbiological quality of some locally produced fast foods. The study was carried out with the hope that results of this study would provide an overview of risks associated with fast foods and offer scientific information to identify the possible source and cause of microbiological contamination.

This study was confined to Dhaka City, where varieties of fast foods are consumed by different classes of people under various environments. It was randomized cross sectional survey conducted in the city. Twenty five grams of the solid or semisolid sample was weighed aseptically into a sterile jar and $225 \mathrm{ml}$ of sterile normal saline was added to it. It was homogenized with sterile blender at $3000 \mathrm{rpm}$ for 5-10 minutes. One ml of homogenate was transferred to a test tube containing $9 \mathrm{ml}$ sterile normal saline to make dilution and mixed thoroughly with a vortex mixer. A serial dilution up to $10^{-5}$ was also made in the same procedure.

Dehydrated media such as MacConkey agar, membrane fecal coliform agar (mFC agar) and Simmon's citrate agar were used for growth and characterization of different bacteria. Other media including plate count agar (PCA), Sabouraud Dextrose agar (SDA), Mannitol Salt agar (MSA), Xylose-Lysine-Dextrose (XLD) agar, MIU agar, Citrate agar, KIA were prepared in the laboratory according to the instruction of the supplier.

The bacterial count was performed by standard method ${ }^{6}$. The microbiological condition of safety and hygiene were then assayed using the methods recommended by $\mathrm{ICMSF}^{7}$. 
Characterization and identification of the isolates was made by various biochemical tests.

The tests for analysis of different types of fast food included total viable bacterial count (TVBC), total coliform count (TCC), total fecal coliform count (TFCC), total Staphylococcus count (TSAC), total Salmonella count (TSC), total fungal count (TFC). The highest total viable bacterial count was $2.7 \times 10^{4} \mathrm{cfu} / \mathrm{g}$ in samosa and lowest count was $1.1 \times 10^{3} \mathrm{cfu} / \mathrm{g}$ in patties. A significant number of bacterial cells were also found in meat kebab and burger (Table 1). Forty four percent (22 of 50) of the samples showed positive result for total coliform. The mean total coliform count was $4.55 \times 10^{2} \mathrm{cfu} / \mathrm{g}$. The highest count was $2.33 \times 10^{3} \mathrm{cfu} /$ $\mathrm{g}$ in fried chicken and lowest count was $3.5 \times 10^{1} \mathrm{cfu} / \mathrm{g}$ in patties (Table 1).

Eight percent (4 of 50) of the samples showed the presence of fecal coliform. The mean total fecal coliform count was $2.15 \times 10^{1}$ $\mathrm{cfu} / \mathrm{g}$. The highest count was $1.9 \times 10^{2} \mathrm{cfu} / \mathrm{g}$ in fried chicken and lowest count was $1.0 \times 10^{1} \mathrm{cfu} / \mathrm{g}$ in patties. About $92 \%$ did not show growth of coliform (Table 1).

On the basis of the cultural, Microscopic and Biochemical characteristics, isolates were presumptively identified.
In the present study the following points were noted which could have served as the source and cause of microbiological contamination; such as, Bare-handed handling of food items, Use of unsafe water by food handlers to wash their hands that had been used over and over again. This water could have been a source of coliform and fecal coliform. Cross contamination between half-cooked and raw meat kept side by side in the same refrigerator may also play role. This could have been a possible source of contamination by Salmonella also. Keeping food for display in glass boxes for a long time at elevated temperatures without refrigeration enable the bacteria to proliferate.

It is the common and traditional practice of Southeast Asian people to handle food items with bare hands. Common pathogens transmitted through bare-handed handling of food are Salmonella spp. and Staphylococcus aureus. S. aureus is a natural skin flora; if food items are contaminated with this organism and the food is kept for a long time in optimum growth temperature, Staphylococcus aureus may grow in the food and produce enterotoxin. For Salmonella species, raw egg is one of the commonest source of contamination. The pathogen may be introduced from raw materials to final products if the eggs used for the sandwiches are not cooked thoroughly. Sandwich, fuchka

Table 1. Average Microbiological counts of different fast foods

\begin{tabular}{lcccccc}
\hline Type of Fast food & \multicolumn{5}{c}{ Microbiological count $(\mathrm{cfu} / \mathrm{g})$} \\
\cline { 2 - 6 } & TVBC & TCC & TFCC & TSAC & TSC & TFC \\
\hline Chicken Sandwich & $3.4 \times 10^{3}$ & $2.33 \times 10^{3}$ & 10 & 17 & $2.0 \times 10^{2}$ & 0 \\
Fried Chicken & $5.0 \times 10^{3}$ & 0 & 0 & 0 & 0 & 0 \\
Chicken Cutlet & $3.8 \times 10^{3}$ & 0 & 0 & 0 & 0 & 0 \\
Pizza & $2.0 \times 10^{3}$ & $1.85 \times 10^{2}$ & 15 & $1.0 \times 10^{2}$ & $1.5 \times 10^{1}$ & 15 \\
Meat Kebab & $1.57 \times 10^{4}$ & 0 & 0 & 0 & 0 & 0 \\
Burger & $1.77 \times 10^{4}$ & $3.5 \times 10^{1}$ & 0 & 0 & $1.3 \times 10^{1}$ & 0 \\
Patties & $1.10 \times 10^{4}$ & $1.20 \times 10^{3}$ & 0 & 5 & $1.47 \times 10^{2}$ & 25 \\
Samosa & $2.70 \times 10^{4}$ & 0 & 0 & 0 & 0 & 13 \\
Singara & $1.77 \times 10^{4}$ & 0 & 0 & 0 & 0 & 30 \\
Vegetable Roll & $2.20 \times 10^{4}$ & $2.5 \times 10^{2}$ & 0 & 17 & $1.97 \times 10^{2}$ & 9
\end{tabular}

Note: Unsatisfactory limit of different bacteria in food items: TVBC, $>10^{5}$

$\mathrm{cfu} / \mathrm{gm}$; TCC, >100 cfu/gm; TFCC, 0/gm; TSAC, 100 - >10 4/gm; TSC, Presence in $25 \mathrm{~g}$; TFC, >100 per $10 \mathrm{~g}$.

Table 3. Presumptive identification of the microorganisms isolated from fast foods

\begin{tabular}{lll}
\hline Type of food & Bacteria & Fungi \\
\hline Chicken sandwich & Escherichia coli, Klebsiella & Aspergillus, Rhizopus \\
Patties & Escherichia coli, Staphylococcus & Mucor, Rhizopus \\
Pizza & Escherichia coli, Klebsiella & \\
Vegetable roll & Escherichia coli, Klebsiella & \\
Burger & Salmonella, Escherichia coli & Aspergillus, Rhizopus \\
Chicken sandwich & Escherichia coli, Klebsiella & \\
\hline
\end{tabular}


and burger preparations involve bare handed handling and thus good personal and environmental hygienic practices should be observed to minimize the chance of cross contaminations. Wearing Hand gloves during handling of such food items can reduce microbiological contamination significantly.

Salmonella spp, Staphylococcus aureus and Listeria monocytogenes are usually introduced in foods by food handlers and cross-contamination between ready-to-eat foods and raw items.

Staphylococcus aureus is naturally present in human nasopharynx. Its presence obviously reflects poor personal and food handling hygiene. Health education and good personal hygiene are important to prevent contamination of food by such bacterial agent. E. coli and coliforms usually contaminate food by the water that is used to wash different utensils and used to wash hands of the food handlers. These contributing factors can be considerably reduced by adequate training of the staffs, implementation of HACCP combined with risk assessment ${ }^{8}$.

Although in low percentages of samples, the presence of the potentially harmful pathogens in some ready to eat food items was alarming and reflected the unsatisfactory sanitary condition of the shops and the personal hygiene of the food handling personnel.

Unlike many developed countries, any major incident of food poisoning in Bangladesh was not common until recently. In the recent past few food poisoning in mass scale have been reported in some newspapers that occurred in feasts of social gatherings, marriage ceremonies etc. in both rural and urban areas. Although no big incidence by fast foods has occurred in our country so far, isolated incidents are heard of which remains uninvestigated. This is due to the absence of monitoring and case study authorities in our country that can carry out a thorough investigation. However, it is a matter of hope that some Mobile Courts have started working in our country to monitor the conditions of different food shops and restaurants. Although these mobile courts are very efficient, their workforce is insufficient. This system must be upgraded by involving more monitoring officials to meet the need.

\section{References}

1. Potter ME. 1978. Proceeding in Food-borne diseases concerns, symposium on Emerging Microbiological Concerns. Leather-Head: Leather Head Food Research Association.

2. Swaminathan M. 1985. Essentials of food and nutrition. pp.16. Vol. 2, 2nd edn. Bangalore Press. India.

3. Medline plus, US National Library of medicine, National Institute of Health (NIH)) http://www.nlm.nih.gov/medlineplus/ency/imagepages/ 19491.htm

4. The New York Times, December 20, 2010.

5. Mansfield LP and Forsythe SJ. 2000. Modern Life and Fast food. Black Academic and Professional, London.

6. Miskimin DK, Berkowitz KA, Sulberg M. Riha WA Jr. and Franke WC. 1976. Specific pathogens in potentially hazardous foods. $J$ Food Sec. 41: 1001-6.

7. ICMSF (International Commission on Microbiological Specification for Foods). 2002. Microorganisms in Foods 7: Microbiological Testing in Food Safety Management. Kluwer Academic/Plenum Publishers, ISBN: 0306472627.

8. Forsythe SJ. 2000. The microbiology of safe food. Distributor: Marson Book Services Ltd. 